\title{
O Ensino do Cálculo numa perspectiva histórica: Da régua de calcular ao MOODLE
}

\author{
Terezinha Ione Martins Torres \\ IPA - Instituto Metodista do Sul \\ ttorres@metodistadosul.edu.br \\ Lucia Maria Martins Giraffa \\ PUCRS/Faculdade de Informática/PUCRS VIRTUAL \\ MEDUCEM/PUCRS VIRTUAL \\ giraffa@ pucrs.br
}

Resumo: Este artigo apresenta uma perspectiva histórica do ensino de Cálculo, considerando aspectos conceituais e tipo de instrumento utilizado para suportar as atividades pedagógicas. $\mathrm{O}$ Cálculo se constitui em um dos temas de estudo, no ensino superior, que possui maior índice de reprovação e evasão por parte dos alunos dos cursos superiores, especialmente nas áreas de Ciências Exatas e Engenharia. O texto apresenta um resgate do ensino de Cálculo no Brasil e ao final apresentam-se algumas considerações a respeito dos artefatos e recursos utilizados para suportar o ensino de Cálculo. Neste sentido apontam-se algumas questões importantes que emergem pela criação do ciberespaço como alternativa de ensino nos dias de hoje.

Palavras-chave: História do Cálculo. Educação Matemática. Metodologias de ensino da Matemática.

\begin{abstract}
This article studies the reasons why Calculus is a subject of greatest difficulty for Science undergraduate students. It also suggests that knowing Calculus History could help students and professors place the subject in the History of Math and understand its importance for the building of Math knowledge.
\end{abstract}

Keywords: History of Calculus, Math Education. History of Math Teaching. 


\section{Introdução}

O conhecimento matemático é, por natureza, encadeado e cumulativo, de modo que o desconhecimento de conceitos elementares pode impedir ou até mesmo dificultar a compreensão dos conceitos subseqüentes. Para nos apropriarmos de um conteúdo, é necessário, entre outros fatores, compreender como ele se estrutura e suas inter-relações com os demais itens que compõem aquele arcabouço de informações para que se construa o conhecimento necessário para se resolver problemas.

É neste contexto que se insere o ensino de Matemática: ele deve capacitar as pessoas para resolverem problemas, usando como recursos seus conhecimentos de Matemática. Isto não só ocorre na área de Matemática, mas também em todas as outras do conhecimento. Neste artigo a discussão se concentra apenas na importância do ensino de Calculo através dos tempos e as crenças de que não se pode estudar um conteúdo sem uma visão contextualizada. Neste aspecto, quando se trata de ensino superior, o contexto deve sempre estar embasado por uma visão histórica, ou seja, acredita-se que para o bom entendimento de um conteúdo ou conceito é necessário que se estabeleçam todas as tessituras entre a área do domínio especifico, no caso o Cálculo, e suas relações transversais com os demais conteúdos a ele associados.

Neste artigo, a proposta é reconstruir a história do Cálculo, considerado como um conteúdo de difícil compreensão por parte dos alunos de cursos superiores. O resgate histórico pretende, através de um conjunto de informações sistematizadas, auxiliar a tornar mais clara a sua relevância tanto para quem ensina, tanto para quem estuda.

O artigo está dividido em 5 seções. A seção 2 apresenta a História do Cálculo numa perspectiva histórica. A seção 3 apresenta aspectos do ensino de Cálculo no Brasil. A seção 4 apresneta uma reflexão sobre os recursos utilizados no ensino de Cálculo. Na seção 5 são apresentadas as considerações finais. Ao final do texto, apresentam-se as referencias bibliográficas utilizadas para elaboração deste artigo.

\section{A origem do Cálculo}

A palavra "calcular" é um diminutivo de "calx", que, em latim, significa "pedra". No passado significou "fazer contas por meios de seixos".

As contribuições dos matemáticos para o nascimento do Cálculo são inúmeras. MOAR (2003) assegura que muitos deles tais como Cavalieri, Barrow, Fermat e Kepler utilizavam conceitos do Cálculo para resolver vários problemas. Porém naquele tempo não existia uma construção logicamente estruturada, ou seja, cada autor possuía sua proposição de como os conteúdos se estruturava dificultando a percepção das inter-relações entre os conteúdos.. 
O desenvolvimento e o aperfeiçoamento das técnicas associadas ao Cálculo aconteceram com Newton e Leibniz, os quais deram origem aos fundamentos mais importantes para o ensino do Cálculo, como a formalização das Derivadas e as Integrais. Segundo MOAR (2003), o Cálculo pode ser dividido em duas partes: uma relacionada às Derivadas ou Cálculo Diferencial e Integral, e outra, relacionada às Integrais, ou simplesmente Cálculo Integral.

O Cálculo Diferencial e Integral ou Derivada possui uma longa história. Sua origem remonta aos babilônios, que utilizavam tabelas de quadrados e de raízes quadradas e cúbicas.

No século XVII, quando Descartes e Pierri Fermat introduziram as coordenadas cartesianas, tornou-se possível a transformação de problemas geométricos em problemas algébricos. Esse estudo veio a facilitar e a criar nova imagem geométrica de funções definidas por relações entre variáveis.

A contribuição de Fermat,segundo MOAR (2003), levou Laplace a considerá-lo o verdadeiro inventor do Cálculo Diferencial, apesar de que, como proposto por Fermat, ainda não possuía a notação apropriada e o conceito de Limites. Somente no século XIX, Cauchy introduziu o conceito de Limite e o conceito de Derivada. Porém, desde o século XVII, com os estudos de Leibniz e Newton, o Cálculo Diferencial já se tornara um instrumento indispensável nos diversos campos da ciência, pela sua grande aplicabilidade.

O Cálculo, no que se refere às Integrais ou Cálculo Integral, surge na história relacionada com os problemas de quadraturas. Esses problemas eram enfrentados pelos gregos na medição de superfícies para determinar suas áreas. Todas as áreas estudadas eram relacionadas à área do quadrado.

De acordo com MAOR (2003, p.61) é aos gregos que se deve a idéia que dá sustentação ao Cálculo:

Geralmente se diz que o Cálculo foi inventado por Issac Newton (1642-1727) e por Gottfried Wilhelm Leibniz (1646-1716) durante a década de 1665-1675, mas isso não é inteiramente verdadeiro. A idéia central por trás do cálculo de usar o processo de limite para derivar resultados sobre objetos comuns, finitos recua até a época dos antigos gregos. Arquimedes de Siracusa (cerca de 290-212 a.C.), o lendário cientista cuja inventividade militar teria desafiado os invasores romanos de sua cidade durante mais de três anos, teria sido um dos primeiros a usar o conceito de limite para calcular a área e o volume de várias formas planas e sólidas.

Uma das maiores contribuições gregas para o Cálculo surgiu em 225 a.C. com Arquimedes. Ele criou o teorema para a quadratura da parábola e o método da exaustão para determinar a área do círculo, obtendo assim, as primeiras aproximações do número "pi". 
BOYER (1992, p.7) assegura que:

Ninguém no mundo antigo iguala-se a Arquimedes, quanto à invenção e à demonstração, ao lidar com problemas relacionados ao cálculo. No entanto, o teorema geral mais antigo em Cálculo não se deve a Arquimedes, mas a matemáticos gregos que viveram, provavelmente, meia dúzia de séculos mais tarde.

Fermat e Johan Bernoulli também contribuíram bastante para o nascimento do Cálculo Integral. Fermat desenvolveu a técnica para determinar a área das "parábolas maiores" através da aritmética do infinito.

Mas nem sempre houve concordância entre estudiosos sobre o tema. Newton e Leibniz tinham duas visões sobre o Cálculo. O primeiro o via como geométrico e, o segundo, como analítico. Do mesmo modo, a história do Cálculo não é única. BARBOSA (2004, p.19), em sua pesquisa, conclui que livros diferentes ressaltam aspectos distintos, concepções múltiplas. Aqui não se pretende discutir a história da Matemática, mas apenas tomá-la como referência para investigar os processos de aprendizagem pelos quais passam os alunos de nossos tempos quando em contato com essa disciplina.

O nome "Cálculo Integral" foi criado por Johann Bernoulli e seu livro publicado pelo seu irmão mais velho, Jacques Bernoulli, em 1690. Leonardo Euler resumiu as idéias de Bernoulli e veio a criar os fundamentos da Análise. Hoje o Cálculo Integral é muito utilizado em áreas do conhecimento humano e aplicado em soluções de problemas de muitos campos de estudo, como Economia, Engenharia, Medicina, Química, Física e Astronomia.

\section{Ensino do Cálculo no Brasil}

Segundo MIORIM (1998, p.80) os métodos modernos do Cálculo Infinitesimal, criados por Newton, Leibniz e Lagrange, constituíram argumento para a introdução da modernização do estudo da Matemática no Brasil no século XX.

Apesar disso, desde o século XVI a Matemática integra o currículo da escola no Brasil.

O ensino secundário brasileiro, entretanto, percorreu um longo caminho desde o descobrimento do Brasil, em pleno Renascimento, até 1931 para começar a ser organizado em um sistema nacional. O ensino de Matemática, também, teve um longo caminho a percorrer. Num primeiro momento, para conseguir que suas várias áreas fossem consideradas importantes para a formação geral do estudante. Num segundo momento, para modernizar seus conteúdos. (MIORIN 1998, p.81) 
O ensino da Matemática no Brasil começou com os jesuítas, que fundaram um colégio no Rio de janeiro em 1573. A educação nas escolas inacianas ${ }^{1}$ tinha como objetivo formar rapazes para servir à Igreja. Os mestres jesuítas preocuparam-se com a inclusão de conteúdos de Matemática no currículo, como o caso do Colégio de Roma, onde o padre Chistopher Clavius (1537-1612) mostrava-se um grande defensor da matemática.

Os padres da Companhia de Jesus, por 200 anos, de modo exclusivo, dominavam o ensino brasileiro e as escolas secundárias difundiam a tradição clássico-humanista que, desde 1599, era chamada de "Ratio atque Institutio Studiorum Societatis jesu" . De acordo com Miorim (1998, p.81), este

Era chamado de código educacional Maximo da Companhia de Jesus. Nessa proposta, na parte equivalente ao ensino médio -os studia inferiora-,defendia-se uma educação baseada apenas nas humanidades clássicas, cujas disciplinas eram a retórica, as humanidades e a gramática. As ciências e em particular as matemáticas eram reservadas apenas aos studia superiora. Entretanto, mesmo nesses estudos superiores, desenvolvidos no curso de filosofia e ciências, ou de artes, pouco estudavam as matemáticas.

Desde a descoberta do Brasil até o ano de 1808, a metrópole proibiu em nosso país a criação de escolas superiores e a circulação e impressão de livros, panfletos e jornais, bem como a existência de tipografia (SILVA, 1999, p.33).

Em 1757, foi criada a Faculdade de Matemática junto ao colégio de Salvador e, a partir da expulsão dos jesuítas, em fins de 1759, os estudantes graduados nas escolas jesuítas não tiveram reconhecimento de seus cursos, devendo prestar exame de equivalência em Coimbra.

Com a expulsão dos jesuítas, o sistema educacional brasileiro desmoronou e surgiram as "aulas régias", aulas avulsas ou de disciplina isolada, como eram conhecidas, que foram criadas com a Reforma Pombalina em Portugal, inspiradas na idéias dos enciclopedistas franceses. Tinham o objetivo de preencher as lacunas deixadas pelas escolas dos jesuítas. Porém estas aulas representaram um retrocesso no ensino, uma vez que não tinham um planejamento de trabalho escolar nem professores com a formação adequada (BARBOSA, 2004, p.31).

Apesar do fracasso das aulas régias, houve um movimento positivo no sentido de modificar os conteúdos escolares, sendo, então, introduzidas novas disciplinas, tais como a Aritmética e a Álgebra. Essas aulas, entretanto, não atingiam um grande público, a frequiência era muito pequena, chegando a ponto de ser lançado um edital do governador de São Paulo com uma ameaça a quem não cumprisse as normas de frequiência às aulas de Geometria.

\footnotetext{
${ }^{1}$ Escolas Inacianas são Escolas jesuítas da congregação de Jesus de Santo Inácio de Loyola.
} 
Também em virtude da expulsão dos jesuítas do Brasil, outros religiosos, como carmelitas e franciscanos, abriram escolas, em cujo currículo não incluíram o estudo da Matemática. Nessa fase, as escolas eram só para meninos. Somente mais tarde foram criadas as escolas elementares para as meninas.

Em 1759, o matemático José Monteiro da Rocha, que estudou na Faculdade de Matemática do Colégio de Salvador, desligou-se da ordem e foi convocado por Marquês do Pombal para compor a equipe que iria reformular a Universidade de Coimbra e também a Faculdade de Matemática, no ano de em 1772. A Matemática ensinada na Faculdade de Salvador na Bahia era a mesma ensinada na Universidade de Coimbra.

Logo a disciplina de Cálculo Diferencial e Integral já fazia parte do currículo do segundo ano da Academia Real Militar, em 1811. Após a chegada de D. João ao Brasil, onde fundou essa Academia, em 1810, o professor Francisco Cordeiro da Silva Torres e Alvim (1775-1856), graduado pela Academia Real dos guardas-marinhas de Lisboa, passou a lecionar Cálculo Diferencial e Integral na Academia.

Em 1837, o ministro e secretário de estado da Justiça e interino do Império, Bernardo Pereira de Vasconcelos, criou a primeira escola secundária pública do Rio de Janeiro, o Colégio Pedro II, e modificou radicalmente os programas do ensino da Matemática, de modo que, Aritmética, Geometria e Álgebra ocupassem seu lugar em todas as oito séries do curso (MIORIM, 1998, p.86).

Mais tarde, com a República, em 8 de novembro de 1890, o primeiro ministro Benjamin Constant baixou um decreto, sob o número 891, deste mesmo ano, em que determinava uma reforma com a eliminação das disciplinas tradicionais, como o latim e o grego e a inclusão do ensino de Matemática abstrata bem como da Matemática concreta. Desse modo, foi introduzido o estudo do Cálculo Diferencial e Integral no terceiro ano. Nenhuma das várias reformas que ocorreram depois da de Benjamin Constant produziu mudanças significativas no ensino brasileiro. Somente na década de 20 começaram as alterações no panorama da Educação em nosso país.

No Brasil, no período de 1920 a 1930, tensões no setor educacional levaram à reforma dos currículos no ensino, principalmente nos currículos do Colégio Pedro II, onde isso aconteceu no ano de 1929, no curso de Matemática Elementar.

Foi o professor catedrático de Matemática Euclides Roxo o maior responsável pela proposta modernizadora brasileira, unificando o estudo de Álgebra, Geometria e Aritmética, que até então eram estudadas separadamente e avaliadas em um exame para cada conteúdo. 
Essa proposta foi homologada pelo decreto número 18564, na data de 15 de janeiro de 1929. Era apenas para o Colégio Pedro II e, apesar de essa Instituição ser considerada um modelo, nada garantia que as outras seguiriam tais orientações.

Três anos depois, de acordo com MIORIN (1998), Francisco Campos fez a primeira tentativa de estruturar o curso Secundário Nacional e de introduzir os princípios modernizadores da Educação, trazendo como idéia principal que a "qualidade da educação não se mede pelo volume de noções e dos conceitos". Foi através dessa reforma que o currículo seriado surgiu, com a frequiência obrigatória em dois ciclos: um fundamental e outro complementar, sendo que a conclusão destes era a exigência para ao ingresso no ensino superior.

\section{Considerações Finais}

O objetivo do ensino da Matemática deixou de ser apenas a busca pelo desenvolvimento do raciocínio lógico-formal mas também como a busca pela compreensão das operações elementares, e pelo senso de estimativa que levariam o aluno a ser um descobridor e não um receptor passivo do conhecimento. Além disso, busca-se a troca do paradigma tradicional baseado da memorização sem raciocínio, para um paradigma que estimula a de resolução de problemas.

Desta forma o ensino de Cálculo que se utilizava a "régua de calcular" proposta apresenta uma visão mais moderna do ensino da Matemática, trazendo uma listagem de conteúdos a serem trabalhados em cada série, em que fica claro o estudo de funções e de Cálculo Infinitesimal. A proposta inovadora de Campos encontrou resistência de muitos professores, que não estavam acostumados a essas novas idéias e por isso sentiam-se inseguros; além do mais, os professores não possuíam livros didáticos com essa nova abordagem.

Hoje, não apenas os livros estão disponíveis, mas também a rede mundial de informações, como a Internet, de modo que alunos e ou professores podem recorrer a materiais de qualidade para ensinar ou aprender Cálculo.

\section{Referências Bibliográficas}

BARBOSA, Marcos Antonio. O insucesso no ensino e aprendizagem na disciplina de cálculo diferencial e integral, 2004. Dissertação (Mestrado em Educação) PUCRS, Curitiba, 2004.

BOYER, Carl Benjamin. Cálculo. Tradução. Hygino H. Domingues. São Paulo: Atual, 1992. (Tópicos de História da Matemática para uso em sala de aula; v. 6). 
MAOR, Eli. E: a história de um número. Tradução de Calife. Rio de Janeiro: Record, 2003.

MIORIM, Maria A. Introdução à história da educação matemática. São Paulo: Atual, 1998.

SILVA, Clovis Pereira. A Matemática no Brasil: uma história de seu desenvolvimento. São Leopoldo: Unisinos, 1999. 